\title{
PENDETEKSIAN TEPI CITRA DIGITAL DENGAN LOGIKA FUZZY
}

\author{
Dedy Kurniawan Hadi Putra ${ }^{1}$, Kushartantya ${ }^{2}$, dan Aris Sugiharto ${ }^{3}$
}

Jurusan Ilmu Komputer / Informatika FSM UNDIP

\begin{abstract}
Metode deteksi tepi citra digital yang sering umum digunakan oleh metode klasik seperti Sobel dan prewit. Selain deteksi tepi dengan metode klasik, ada metode lain, yaitu deteksi tepi dengan logika fuzzy. Logika fuzzy mampu mengatasi ambiguitas dan ketidakjelasan gambar dengan benar, seperti perbedaan membatasi tingkat kecerahan gambar. Logika Fuzzy dianggap mampu menangani proses deteksi tepi. Deteksi tepi citra digital dengan logika fuzzy dimulai dengan mengelompokkan tingkat kecerahan pada set kelompok kabur yaitu hitam dan putih. Kelompok ini membentuk himpunan fuzzy fungsi keanggotaan fuzzy. Beberapa aturan yang digunakan sebagai filter dengan ukuran 3x3 piksel, untuk menentukan tepi, piksels hitam dan putih, dinyatakan dalam fungsi keanggotaan fuzzy output. Proses defuzzifikasi dilakukan untuk mendapatkan nilai output dalam bentuk tingkat kecerahan matriks. Thresholding digunakan untuk memisahkan piksel tepi dengan piksel hitam dan putih. Tepi piksel ditunjukkan dengan nilai 1 dan piksel hitam atau putih dengan nilai 0 . Citra output menunjukkan tepi gambar input.
\end{abstract}

Kata kunci: citra digital, deteksi tepi, logika fuzzy, aturan inferensi fuzy

\section{PENDAHULUAN}

Pada jaman modern sekarang ini, citra dalam bentuk digital dapat dengan mudah dijumpai. Pemanfaatan citra digital dalam berbagai bidang juga sudah menjadi hal yang umum digunakan. Berbeda dengan citra analog, citra digital lebih luas pemanfaatannya karena kemudahan dalam hal penyimpanan dan pengolahan. Penggunaan citra digital antara lain fotografi digital, gambar rancang bangun, peta digital, sidik jari dan banner halaman web.

Pengolahan citra digital dilakukan dengan pemanfaatan teknologi komputer. Pengolahan citra bermanfaat untuk mempermudah didapatkannya informasi dari suatu citra digital baik berupa suatu citra hasil olahan maupun parameter yang terkait dengan citra tersebut. Dalam kehidupan sehari-hari pengolahan citra digunakan untuk memperbaiki kualitas gambar fotografi, pendeteksian otomatis kecacatan produk tekstil, manipulasi gambar pada industri film, pengenalan sidik jari dan lain sebagainya. Salah satu jenis pengolahan citra adalah pendeteksian tepi.

Secara umum pendeteksian tepi suatu citra digital dapat diartikan sebagai suatu proses yang menghasilkan tepi-tepi dari obyek-obyek yang terdapat dalam citra digital tersebut.
Pendeteksian tepi merupakan proses awal dari pengenalan pola yang dalam kehidupan seharihari diterapkan di berbagai hal, antara lain pengenalan wajah, identifikasi sidik jari, dan rekam medis di mana batas-batas wilayah tertentu diperlukan untuk analisis citra lebih lanjut[4]. Pendeteksian tepi merupakan bagian dari analisis citra. Analisis citra diawali dengan proses ekstraksi ciri (feature extraction). Pendeteksian tepi adalah faktor kunci dalam mengekstrasi ciri, yang sangat penting untuk melaksanakan analisis citra[13]. Beberapa metode klasik yang sudah sering diaplikasikan untuk pendeteksian tepi adalah metode Prewitt dan Sobel.

Selain metode-metode klasik tersebut terdapat juga metode pendeteksian tepi dengan memanfaatkan logika fuzzy [3]. Logika fuzzy berkemampuan mengatasi ambiguitas dan kekaburan image dengan baik seperti pembedaan batas warna. Dengan demikian Logika Fuzzy dianggap mampu untuk menangani proses pendeteksian tepi [15].

Logika fuzzy pertama kali diperkenalkan oleh Lofti A. Zadeh dari Universitas Barkley, California pada tahun 1965. Zadeh memodifikasi teori himpunan yang setiap anggotanya memiliki derajat keanggotaan yang bernilai kontinu antara 
0 sampai 1 yang digunakan untuk menangani kekaburan. Himpunan ini disebut dengan himpunan kabur (fuzzy set). Logika fuzzy adalah suatu cara yang tepat untuk memetakan suatu ruang input ke dalam suatu ruang output [10].

Sistem Inferensi Fuzzy adalah suatu kerangka komputasi yang didasarkan pada teori himpunan fuzzy, aturan fuzzy, dan penalaran fuzzy [11]. Sistem Inferensi Fuzzy dapat dilakukan dengan tiga metode, yaitu dengan metode Mamdani, metode Sugeno dan metode Tsukamoto [10]. Perbedaan dari ketiga metode tersebut terletak pada output yang dihasilkan. Metode Mamdani menghasilkan output berupa variabel. Metode Tsukamoto mempunyai output berupa angka, sedangkan Metode Sugeno menghasilkan output berupa persamaan linier. Melihat kebutuhan dari proses pendeteksian tepi yang melibatkan pengelompokan graylevel(tingkat keabu-abuan) dari o-255 (citra 8bit) menjadi hitam, putih dan tepi, metode yang digunakan adalah Metode Mamdani.

Dalam penelitian ini, berdasarkan analisa peneliti akan dibuat aplikasi menggunakan Sistem Inferensi Fuzzy dengan metode Mamdani untuk pendeteksian tepi suatu citra digital..

\section{TINJAUAN PUSTAKA}

Tinjauan Pustaka berisi kumpulan studi pustaka yang berhubungan dengan topic penelitian. Dasar teori ini meliputi teori yang mendukung proses pengembangan sistem meliputi konsep dasar citra digital, pengolahan citra digital, logika fuzzy, inferensi fuzzy, data flow diagram (DFD), flowchart, dan juga tentang Matlab

\subsection{Citra Digital}

Citra digital dapat didefinisikan sebagai fungsi dua variabel, $f(x, y)$ di mana $x$ dan $y$ adalah koordinat spasial dan nilai $\mathrm{f}(\mathrm{x}, \mathrm{y})$ adalah intensitas citra pada koordinat tersebut [8]

Secara matematis fungsi intensitas cahaya pada bidang dwimatra disimbolkan dengan $f(x$, $y$ ), yang dalam hal ini:

$$
\begin{aligned}
(x, y) & \text { : koordinat pada bidang } \\
& \text { dwimatra. }
\end{aligned}
$$

$$
\begin{aligned}
& f(x, y): \text { intensitas cahaya (brightness) pada } \\
& \text { titik }(x, y)
\end{aligned}
$$

\subsection{Ekstensi Citra Digital}

Citra Digital memiliki beberapa ekstensi yang memiliki karakteristik.tersendiri. Ekstensi pada citra digital umumnya berdasarkan tipe dan cara kompresi yang digunakan pada citra digital tersebut. Beberapa macam ekstensi citra digital, antara lain PNG, JPEG, TIFF, dan BMP.

\subsection{Pendeteksian Tepi}

Secara umum pendeteksian tepi suatu citra digital dapat diartikan sebagai suatu proses yang menghasilkan tepi-tepi dari obyek-obyek yang terdapat dalam citra digital tersebut. Adapun yang dimaksud dengan tepi (edge) adalah perubahan nilai intensitas derajat keabu-abuan yang mendadak (besar) dalam jarak singkat. Tepi biasanya terdapat pada batas antara dua daerah berbeda pada suatu citra. Tepi dapat diorientasikan dengan suatu arah, dan arah ini berbeda-beda, bergantung pada perubahan intensitas[13].

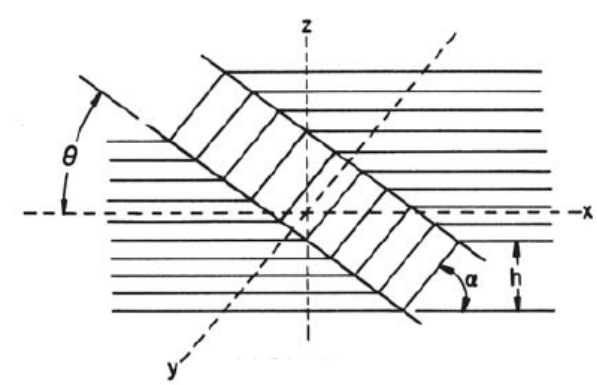

Gambar 1 Model tepi dua matra [17]

$$
\begin{aligned}
& \mathrm{Z}: \text { skala kecerahan } \\
& \alpha: \text { sudut pergeseran } \\
& \mathrm{h}: \text { perubahan kecerahan }
\end{aligned}
$$

Ada tiga macam tepi yang terdapat di dalam citra digital[13], yaitu:

\section{Tepi curam}

Tepi dengan perubahan intensitas yang tajam.

Arah tepi berkisar $90^{\circ}$.

2. Tepi landai 
Disebut juga tepi lebar, yaitu tepi dengan sudut arah yang kecil. Tepi landai dapat dianggap terdiri dari sejumlah tepi-tepi lokal yang lokasinya berdekatan.

3. Tepi yang mengandung derau (noise)

Umumnya tepi yang terdapat pada aplikasi computer vision mengandung derau. Operasi peningkatan kualitas citra (image enhancement) dapat dilakukan terlebih dahulu sebelum pendeteksian tepi.
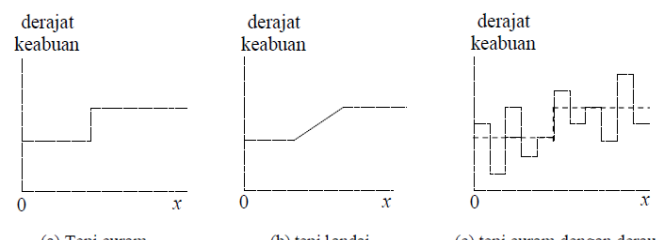

Gambar 2 Jenis-jenis tepi [13]

Tujuan pendeteksian tepi adalah untuk meningkatkan penampakan garis batas suatu daerah atau objek di dalam citra. Pendeteksian tepi merupakan langkah pertama untuk melingkupi informasi di dalam citra. Tepi mencirikan batas-batas objek dan karena itu tepi berguna untuk proses segmentasi dan identifikasi objek di dalam citra[13].

Terdapat beberapa teknik yang digunakan untuk mendeteksi tepi[13], antara lain:
1. Operator gradien pertama (differential gradient)

2. Operator turunan kedua (laplacian)

3. Operator kompas (compass operator).

\subsection{Logika Fuzzy}

Logika fuzzy pertama kali diperkenalkan oleh Lofti A. Zadeh dari universitas Barkley, California pada tahun 1965. Zadeh memodifikasi teori himpunan yang setiap anggotanya memiliki derajat keanggotaan yang bernilai kontinu antara 0 sampai 1 yang digunakan untuk menangani kekaburan. Himpunan ini disebut dengan himpunan kabur (fuzzy set). Logika fuzzy adalah suatu cara yang tepat untuk memetakan suatu ruang input ke dalam suatu ruang output [10]. Logika fuzzy digunakan untuk menterjemahkan suatu besaran yang diekspresikan menggunakan bahasa (linguistic), misalkan besaran kecepatan laju kendaraan yang diekspresikan dengan pelan, agak cepat, cepat, dan sangat cepat. Logika fuzzy menunjukan sejauh mana suatu nilai itu benar dan sejauh mana suatu nilai itu salah, sedangkan logika klasik (crisp)/tegas, suatu nilai hanya mempunyai 2 kemungkinan yaitu merupakan suatu anggota himpunan atau tidak. Derajat keanggotaan $0 \quad$ (nol) artinya nilai bukan merupakan anggota himpunan dan 1 (satu) berarti nilai tersebut adalah anggota himpunan.

Logika fuzzy adalah suatu cara yang tepat untuk memetakan suatu ruang input kedalam suatu ruang output [10].

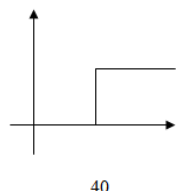

(Logika tegas/crisp)

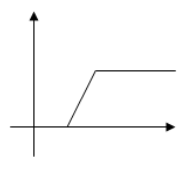

(Logika fuzzy)
Gambar 3 Perbedaan logika tegas dan logika fuzzy

\subsection{Sistem Inferensi Fuzzy}

Template matching Sistem Inferensi Fuzzy (Fuzzy Inference System/FIS) disebut juga fuzzy inference engine adalah sistem yang dapat melakukan penalaran dengan prinsip serupa seperti manusia melakukan penalaran dengan nalurinya. FIS tersebut bekerja berdasarkan kaidah-kaidah linguistik dan memiliki algoritma fuzzy yang menyediakan sebuah aproksimasi untuk dimasuki analisa matematik. Terdapat beberapa jenis FIS yang dikenal yaitu[10]:

1. Metode Tsukamoto

Pada metode Tsukamoto, setiap konsekuen pada aturan yang berbentuk If-Then harus direpresentasikan dengan suatu himpunan fuzzy dengan fungsi keanggotaan yang monoton. Sebagai hasilnya, output hasil inferensi dari tiaptiap aturan diberikan secara tegas (crips) berdasarkan a-predikat (fire strength). Hasil 
akhimya diperoleh dengan menggunakan ratarata terbobot.

2. Metode Sugeno

Penalaran dengan metode Sugeno diperkenalkan oleh Takagi Sugeno Kang pada tahun 1985. Pada metode penalaran atau rule evaluatian Takegi Sugeno, output sistem tidak berupa himpunan fuzzy, melainkan berupa konstanta atau persamaan linear. Penelitian ini menggunakan model Fuzzy Sugeno Orde-Nol. Secara umum bentuk model fuzzy Sugeno orde nol adalah:

\section{IF ( $(x 1$ is $\mathrm{A1}) \mathrm{o}(\mathrm{x} 2$ is $\mathrm{A2}) \mathrm{o}(\mathrm{x} 3$ is $\mathrm{A3}) \ldots \mathrm{o}(\mathrm{xN}$ is AN) THEN $z=k$}

Ai adalah himpunan fuzzy ke-i sebagai anteseden,

$\mathrm{k}$ adalah suatu konstanta (tegas) sebagai konsekuen.

\section{Metode Mamdani}

Metode mamdani sering juga dikenal dengan nama metode min-max. Metode ini diperkenalkan oleh Ebrahim Mamdani pada tahun 1975. Untuk mendapatkan output diperlukan 4 tahapan, yaitu pembentukan himpunan fuzzy, aplikasi fungsi implikasi, komposisi aturan, dan penegasan (defuzzy).

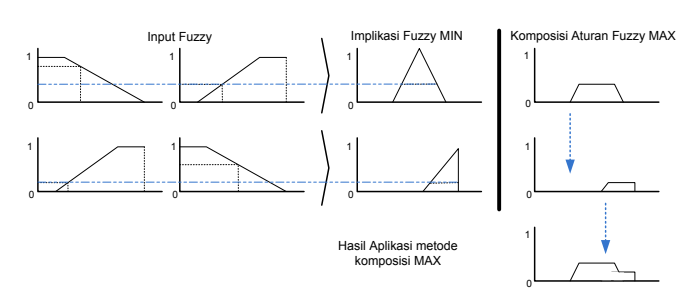

Gambar 4 Inferensi dengan metode Mamdani

\section{ANALISIS DAN PERANCANGAN SISTEM}

Pada Analisis dan Perancangan Sistem akan dijelaskan kebutuhan untuk membangun sistem, yang meliputi analisis kebutuhan, DFD, perancangan proses pendeteksian tepi dengan logika fuzzy, dan perancangan antarmuka aplikasi.

\subsection{Analisis Kebutuhan}

Perangkat Perangkat lunak pendeteksian tepi citra digital dengan logika fuzzy digunakan untuk menemukan piksel-piksel tepi dari suatu masukan yang berupa citra digital. Dalam membangun perangkat lunak pendeteksian tepi ini, diperlukan analisis kebutuhan yang jelas sebagai tujuan utamanya agar tidak keluar dari rencana yang telah ditetapkan. Beberapa kemampuan sistem yang didefinisikan diantaranya adalah:

1) Memiliki kemampuan untuk memasukkan file citra digital berwarna (RGB) maupun citra grayscale (8bit) dengan ekstensi *.bmp, *.png, *.tiff maupun *.jpg sebagai citra masukan.

2) Memiliki kemampuan untuk secara otomatis mengkonversi citra yang diinputkan dari RGB ke citra grayscale (8bit).

3) Memiliki kemampuan untuk menampilkan tumbnail dari citra masukan.

4) Memiliki kemampuan untuk melakukan pendeteksian tepi pada citra masukan dengan menggunakan metode logika fuzzy.

5) Memiliki kemampuan untuk menampilkan tumbnail citra hasil pendeteksian tepi.

6) Memiliki kemampuan untuk menyimpan citra hasil pendeteksian tepi dengan pilihan file format *. bmp, *.png, *.tiff maupun *.jpg.

\subsection{DFD}

Data Flow Diagram adalah satu alat pembuatan model grafis yang menggambarkan aliran informasi dan transformasi yang diaplikasikan pada saat data bergerak dari input menjadi output. Pendefinisian dengan menggunakan DFD level 0 memberikan gambaran data yang mengalir antara sistem dengan lingkungan yang digambarkan secara global. Gambar 5. menjelaskan bahwa pengguna dapat memberikan masukan kepada sistem berupa citra masukan dan batasan membership input fuzzy yang diinginkan. Pengguna memperoleh citra keluaran yang berupa hasil ekstraksi tepi sebagai output. 


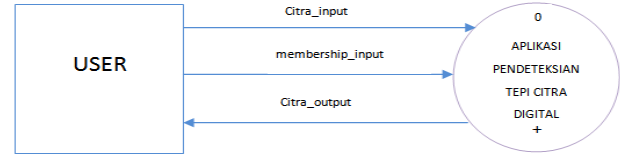

Gambar 5. DFD Level 0 Sistem pendeteksian tepi dengan logika fuzzy

Dari Data Flow Diagram level 0 pada gambar 5, maka dapat dibuat sebuah Data Flow Diagram yang lebih rinci lagi, seperti pada gambar 6.

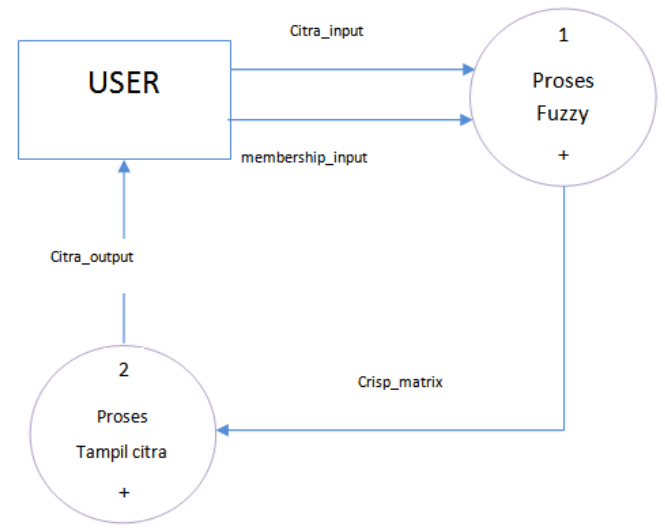

Gambar 6. DFD Level 1 pendeteksian tepi dengan logika fuzzy

DFD Level 2 proses 1 (Proses Fuzzy) terdapat tiga buah proses, yaitu :

1) Proses Fuzzyfikasi (1.1), yaitu proses modifikasi variabel citra akan dirubah dari nilai level keabu-abuan (gray-level) menjadi nilai keanggotaan fuzzy (fuzzy membership values)

2) Proses modifikasi nilai keanggotaan (modification of membership value) (1.2), pada tahapan ini hasil dari image fuzzification yang berupa fuzzy sets akan diproses menggunakan beberapa fuzzy rule. Hasil yang akan didapatkan pada akhir tahapan ini adalah fuzzy sets yang dikelompokkan berupa beberapa variabel yaitu black, white dan edge.
3) Proses Defuzzifikasi (defuzzification) (1.3) yaitu proses pencarian nilai crisp dari output proses sebelumnya. Output dari proses defuzzyfikasi ini berupa tingkat keabu-abuan.

Pada DFD Level 2 proses 2 (Proses Tampil Citra) terdapat dua buah proses, yaitu :

1) Proses Thresholding (2.1) adalah proses mengubah citra berderajat keabu-abuan menjadi citra biner atau hitam putih sehingga dapat diketahui daerah mana yang termasuk obyek dan background dari citra secara jelas.

2) Proses Tampil Citra Hasil (2.2), yaitu proses menampilkan citra hasil kepada pengguna.

Gambaran mengenai DFD (data flow diagram) Level 2, dapat dilihat pada Gambar 7.

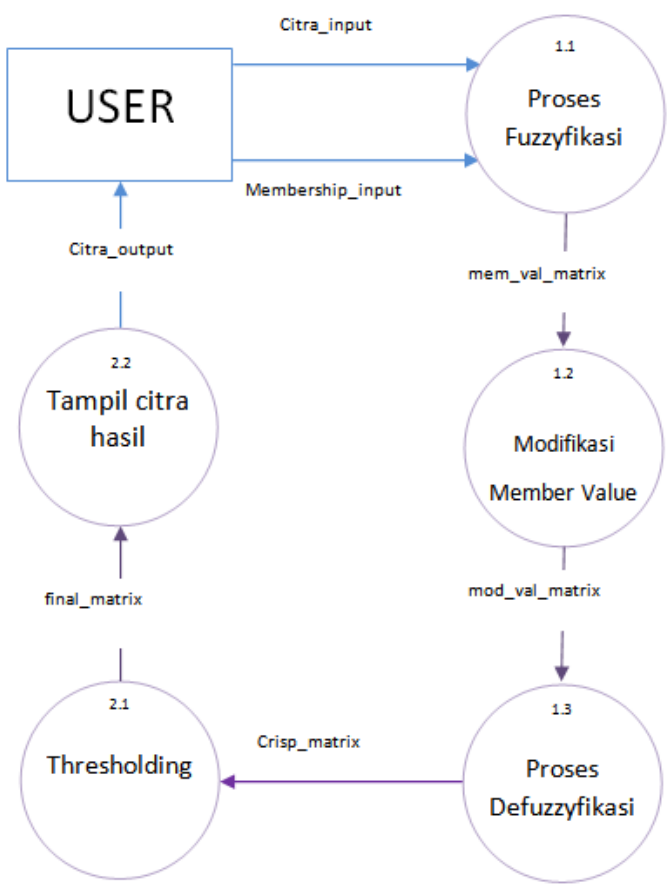

Gambar 7. DFD Level 2

Perancangan Proses Pendeteksian Tepi Citra Digital dengan Logika Fuzzy

Perancangan proses pendeteksian tepi citra digital dengan logika fuzzy merupakan deskripsi dari kebutuhan yang direpresentasikan ke dalam 
perangkat lunak sebelum dimulai pembuatan kode program. Perancangan tersebut meliputi diagram alur (flowchart) dari aplikasi pendeteksian tepi citra digital dengan logika fuzzy.

Terdapat dua proses utama yang ada dalam aplikasi pendeteksian tepi citra digital dengan logika fuzzy, yaitu :

1) Proses Fuzzy, yaitu proses pengekstraksian tepi dari suatu citra masukan menggunakan fungsi inferensi fuzzy.

2) Proses tampil citra output, yaitu proses untuk menampilakn citra keluaran kepada pengguna.

Flowchart dari aplikasi pendeteksian tepi citra digital dengan logika fuzzy dapat dilihat pada Gambar 8 .

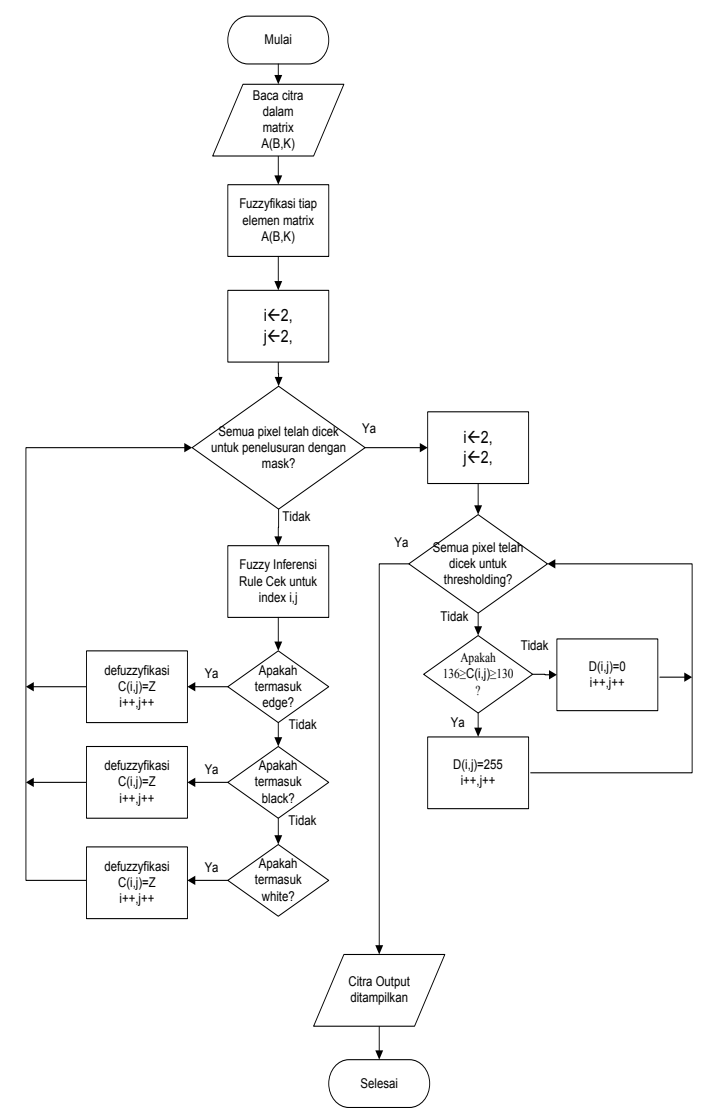

Gambar 8. Flowchart pendeteksian tepi dengan logika fuzzy .

\section{PENGUJIAN, DAN ANALISIS HASIL}

Pengujian aplikasi pendeteksian tepi citra digital dengan logika fuzzy dilakukan dengan mencoba melakukan pendeteksian tepi terhadap beberapa citra dan dibandingkan dengan hasil dari pendeteksian tepi dengan metode Sobel dan Prewitt.

Pengujian aplikasi pendeteksian tepi citra digital dengan logika fuzzy dilakukan dengan percobaan pendeteksian tepi terhadap beberapa citra digital. Citra digital yang digunakan untuk pengujian adalah citra tes yang umum digunakan untuk beberapa uji pengolahan citra yang dapat diunduh secara gratis untuk keperluan penelitian pada website Signal and Image Processing Institute, University of Soutern California. Masing-masing citra masukan akan diuji dengan 3 kombinasi nilai input yang berbeda berupa batas himpunan keanggotaan fuzzy input black dan white. Masing- masing citra input juga akan di lakukan proses pendeteksian tepi dengan metode sobel dan prewit sebagai pembanding. Screenshoot dari salah satu pengujian menggunakan aplikasi pendeteksian tepi citra digital dengan logika fuzzy yang dilakukan akan ditampilkan dalam Gambar 9

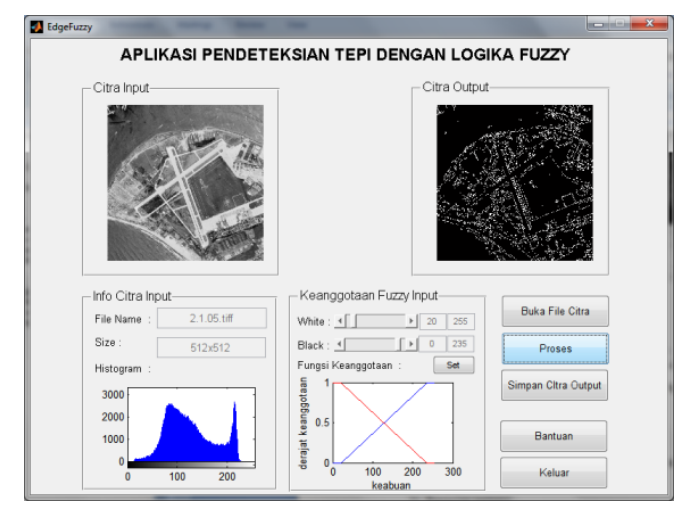

Gambar 9. Screeshoot Pengujian Aplikasi

Salah satu hasil pengujian aplikasi pendeteksian tepi citra digital dengan logika fuzzy adalah sebagai berikut : 
Tabel 4.1. Hasil Pengujian 1

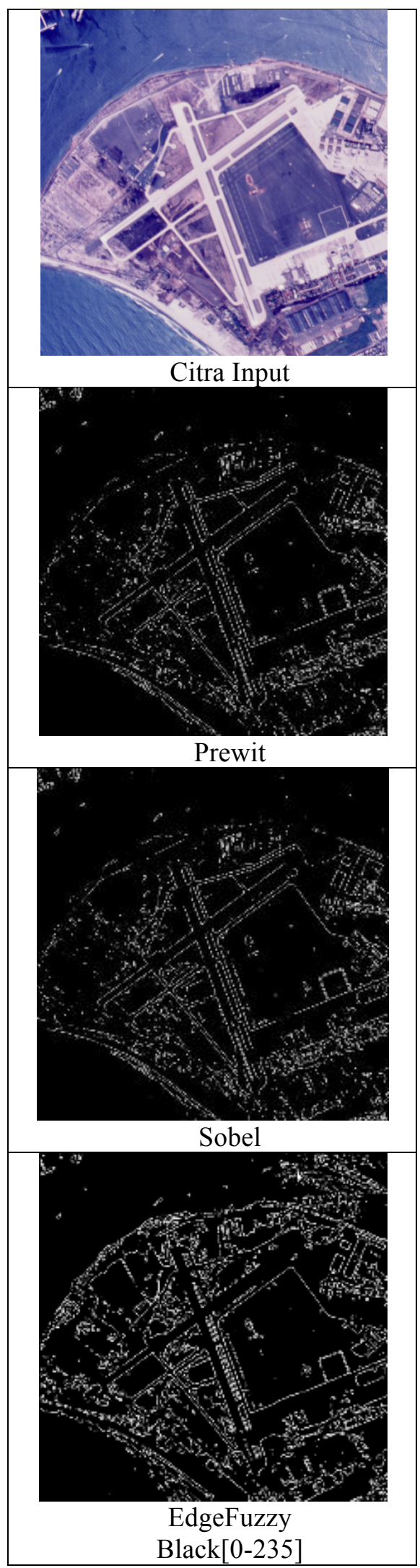

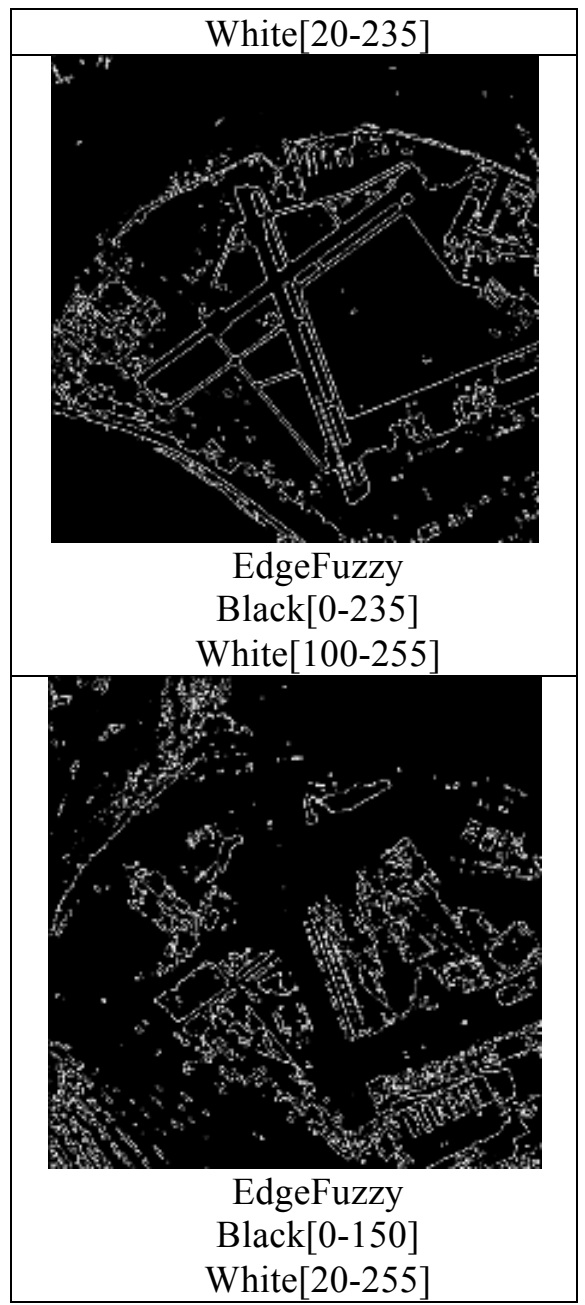

Dari pengujian aplikasi pendeteksian tepi citra digital dengan logika fuzzy yang telah dilakukan dapat diambil beberapa poin penting, antara lain:

1) Aplikasi pendeteksian citra digital dengan logika fuzzy dapat mengekstraksi tepi dari citra yang diujikan.

2) Dari hasil pengujian 1, 2 dan 3 dengan menggunakan masing-masing tiga nilai keanggotaan fuzzy input yang berbeda diketahui citra output hasil pendeteksian tepi dengan logika fuzzy sangat bergantung dengan batas himpunan keanggotaan yang diinputkan.

3) Aplikasi pendeteksian tepi dengan logika fuzzy memberikan kebebasan kepada user 
untuk menentukan batas keanggotaan fuzzy input agar diperoleh hasil yang diinginkan.

4) Pada citra output hasil pendeteksian tepi dengan logika fuzzy masih terlihat beberapa titik noise dari pada hasil dari metode sobel dan prewit.

\section{KESIMPULAN}

Kesimpulan yang dapat diambil dalam penelitian ini adalah :

1. Metode logika fuzzy dapat diaplikasikan sebagai salah satu cara pendeteksian tepi.

2. Citra output hasil pendeteksian tepi dengan logika fuzzy sangat bergantung dengan batas himpunan keanggotaan inputnya.

3. Pendeteksian tepi dengan logika fuzzy memberikan kebebasan kepada user untuk menentukan batas keanggotaan fuzzy input agar diperoleh hasil yang diinginkan.

4. Diperlukan beberapa kali ujicoba dengan berbagai kombinasi batas keanggotaan sebagai masukan untuk memperoleh hasil yang diinginkan.

5. Pada citra output hasil pendeteksian tepi dengan logika fuzzy masih terlihat beberapa titik noise dari pada hasil dari metode sobel dan prewit

Penelitian ini masih dapat dikembangkan lebih lanjut. Adapun saran untuk mengembangkan penelitian ini adalah dapat digunakannya metode noise filtering agar dapat diperoleh citra output yang lebih bebas noise.

\section{DAFTAR PUSTAKA}

[1]___., "MATLAB", diakses dari http://www.mathworks.com/products/ matlab/, pada tanggal 21 Agustus 2013, pukul 19.00 WIB

[2]__, "Raster Image", diakses dari http://www.fileinfo.com/

filetypes/raster_image, pada tanggal 14 Agustus 2013, pukul 19.00 WIB
[3]Abdallah A. Alshennawy, dan Ayman A. Aly, 2009, "Edge Detection in Digital Images Using Fuzzy Logic Technique", World Academy of Science, Engineering and Technology 51

[4] Aborisade, D.O, "Fuzzy Logic Based Digital Image Edge Detection", Department of Electronics Engineering, Ladoke Akintola University of Technology.

[5]Ahmad, Usman., 2005, "Pengolahan Citra Digital \& Teknik Pemrogramannya", Graha Ilmu, Yogyakarta.

[6] Anharku., 2009, "Flowchart", diakses dari ilmukomputer.org/wpcontent/uploads/2009/06/anharku-

flowchart.pdf, pada tanggal 16 Agustus 2013, pukul 21.00 WIB.

[7] Ford, A, and Roberts, A., 1998, "Color Space Coversions", diakses dari http://www.poynton.com/PDFs/coloureq.pdf, pada tanggal 16 Agustus 2013, pukul 09.00 WIB.

[8] Gonzalez, Rafael., 2002, "Digital Image Processing 2nd Edition", USA:AddisonWesley Publishing Co, University of Tenesse.

[9]Ian Sommerville, 2011, "Software Engineering", Pearson Education, Inc, Massachusetts

[10] Kusumadewi, S. dan H. Purnomo, 2004, “Aplikasi Logika Fuzzy untuk Pendukung Keputusan", Graha Ilmu, Yogyakarta.

[11] Kusumadewi, S. dan S. Hartati, 2006, "Neuro-Fuzzy: Integrasi Sistem Fuzzy dan Jaringan Syaraf", Graha Ilmu, Yogyakarta.

[12] Leman., 1998, "Metodologi Pengembangan Sistem Informasi", Jakarta:Elex Media Komputindo.

[13] Munir, Rinaldi, 2004, "Pengolahan Citra Digital dengan Pendekatan Algoritmik", Informatika Bandung, Bandung

[14] Pressman, Roger S., 2002, "Rekayasa Perangkat Lunak", Yogyakarta: Penerbit ANDI. 
[15] Shashank Mathur, dan Anil Ahlawat, 2008, “Application Of Fuzzy Logic on Image Edge Detection", Makalah ini terpilih pada Konferensi International "Intelligent Information and Engineering Systems" INFOS 2008, Varna, Bulgaria, June-July 2008
[16] UrRahman Aijaz, dan Kavita Thakur, 2012,"An Efficient Fuzzy Logic Based Edge Detection Algorithm for Grayscale Image",Chhattisgarh, India

[17] William K.Pratt, 2007, "Digital Image Processing", Fourth Edition, Wiley Interscience, California 
Dedy Kurniawan Hadi Putra, Kushartantya, dan Aris Sugiharto 